\title{
A CONSTRUÇÃO DA REFERÊNCIA POR MEIO DE TRAÇOS DE SENTIDOS EM UMA NARRATIVA DE SUSPENSE PRODUZIDA POR ALUNOS DE $9^{\circ}$ ANO
}

\author{
THE CONSTRUCTION OF THE REFERENCE BY MEANS OF SENSES IN A \\ NARRATIVE OF SUSPENSE PRODUCED BY STUDENTS OF 9TH YEAR OF \\ ELEMENTARY SCHOOL
}

\author{
José Alves Ferreira Neto ${ }^{1}$ \\ Valdinar Custódio Filho ${ }^{2}$
}

Resumo: Este artigo tem como objetivo analisar as estratégias de referenciação construídas em uma narrativa de suspense escrita por alunos de $9^{\circ}$ ano. A produção textual é resultado de nossa proposta de intervenção vinculada ao Mestrado Profissional em Letras da Universidade Estadual do Ceará. A proposta de intervenção foi aplicada em uma turma de uma escola pública municipal de Fortaleza, a fim de potencializar, pragmática e discursivamente, a produção escrita dos aprendizes, a partir do desenvolvimento das estratégias de referenciação. Consideramos que os processos de referenciação estudados ajudaram os discentes a apresentarem uma escrita mais eficaz, o que se revela pelo domínio que demonstraram para transformar, textualmente, os referentes principais do texto produzido.

Palavras-chave: estratégias de referenciação; recategorização; ensino de produção textual.

\begin{abstract}
This article aims to analyze the reference strategies built in a narrative which contains a surprise element, written by 9th grade students. The textual production is the result of our intervention proposal linked to the Professional Master's Degree in Language Teaching of the State University of Ceará. The intervention proposal was applied in a class of a municipal public school in Fortaleza, in order to potentialize, pragmatically and discursively, the written production of apprentices, starting from the development of reference strategies. We consider that the processes of reference studied helped the students to present a more effective writing, which was revealed through the demonstration that students could change, in an effective way, the main referents of their text.
\end{abstract}

Keywords: referentiation strategies; recategorization; teaching of textual production.

\section{Introdução}

\footnotetext{
${ }^{1}$ Mestre em Letras pela Universidade Estadual do Ceará. Professor efetivo da Secretaria Municipal de Educação de Fortaleza e da Secretaria da Educação do Ceará. E-mail: jfnetoce@ gmail.com.

2 Doutor em Linguística pela Universidade Federal do Ceará. Professor adjunto I da Universidade Estadual do Ceará (UECE). E-mail: valdinar.filho@uece.br.
} 
O processo de referenciação representa uma área importante nos estudos linguísticos. Os estudiosos do assunto, como Mondada e Dubois (2003), postulam que a referência é um ato de elaboração criativa e situada da realidade, que envolve experiências e percepções no funcionamento da língua como atividade cognitiva e sociodiscursiva. A partir dessa concepção, as atividades de compreensão e produção textual são (re)dimensionadas como resultantes de diversas ações de produção de sentidos, que podem auxiliar no desenvolvimento da competência discursiva dos aprendizes.

Neste trabalho, investigamos a aplicação do fenômeno relacionado ao ensinoaprendizagem de Língua Portuguesa, especialmente no que diz respeito à intervenção do professor como um mediador, que atua efetivamente para colaborar com a construção dos sentidos nas produções textuais dos discentes. Nossa proposta de intervenção é proveniente da nossa pesquisa no âmbito do Mestrado Profissional em Letras (ProfLetras) da Universidade Estadual do Ceará (UECE). Assim, analisamos como os aprendizes de uma turma de $9^{\circ}$ ano, com o intermédio do professor, produziram seu texto, a partir do desenvolvimento das estratégias de referenciação conforme o proposto por Custódio Filho (2011), que preconiza a construção da referência por meio de traços de sentidos.

O artigo se organiza em duas seções: na primeira, falamos, brevemente, sobre o fenômeno da referenciação, destacando o papel da estratégia de recategorização, além de discorremos sobre a proposta de análise dos processos referenciais a partir dos traços de sentidos, de acordo com Custódio Filho (2011); na segunda, demonstramos nossa análise e discutimos os resultados obtidos, além de refletir sobre a pertinência de se aplicar, na prática docente, o que é preconizado pelo arcabouço teórico da Linguística Textual.

\section{0 papel da estratégia de recategorização no processo de referenciação textual}

A referenciação é um dos fenômenos textual-discursivos mais importantes para o entendimento sobre como ocorre a produção e a compreensão dos sentidos dos textos. Seguindo os pressupostos preconizados por Mondada e Dubois (2003), verifica-se que a abordagem textual-discursiva da referenciação fundamenta-se no paradigma sociocognitivista (KOCH e CUNHA-LIMA, 2003; CUSTÓDIO FILHO, 2011), o qual estabelece a constatação de três princípios basilares:

- a referenciação é uma (re)elaboração da realidade, uma vez que as categorias são inerentemente instáveis nos usos efetivos da linguagem, o que evidencia 
que os objetos de discurso sofrem transformações de acordo com as particularidades e restrições de cada situação interativa;

- a referenciação é um processo resultante da negociação entre os interlocutores da interação comunicativa, o que significa que os sujeitos sempre negociam os sentidos que constroem ao interagirem ativamente, através de $\operatorname{acordos}^{3}$ que garantem a progressão dos objetos de discurso;

- a referenciação se caracteriza pela natureza sociocognitiva dos objetos textualmente acionados, uma vez que há uma relação fundamental entre o processo de conhecer, aspecto da cognição, e as experiências culturais, aspecto do social, de modo que esses dois planos - o cognitivo e o social - não são apartados um do outro.

Faz-se importante destacar que esses princípios possibilitam avaliar a construção da referência como um processo que favorece, de modo fundamental, o caráter dinâmico que constitui a linguagem. O processo de referir, a partir desses pressupostos, não pode ser visto apenas como uma relação direta na qual a língua representa as categorias do mundo. Pelo contrário, o que se evidencia, sobretudo, é que o processo de referenciação preconiza que a realidade, assim como a linguagem, não está pronta e acabada, mas é construída e reconstruída a partir das atividades cognitivo-discursivas que os sujeitos realizam no dinâmico processo de interação, a partir do projeto de dizer dos enunciadores (LIMA, 2016).

Diante do exposto, assumimos que o processo de referenciação diz respeito ao conjunto de operações dinâmicas, sociocognitivamente motivadas, que os sujeitos efetuam, à medida que o discurso se desenvolve, com o objetivo de promover as experiências vividas, de acordo com a construção partilhada dos objetos de discurso que garantem a construção de sentidos (CAVALCANTE, 2012).

No panorama dos estudos sobre referenciação, destaca-se o papel da recategorização referencial, que consiste na transformação dos objetos de discurso, na construção dos sentidos via textos. Assim, essa estratégia possibilita o acréscimo de novas informações, novos traços, o que significa que os referentes sofrem variações de natureza discursiva, por isso se modificam no seu desenvolvimento dentro da tessitura textual. Toda essa evolução é essencial para a progressão das ideias do texto, construindo o projeto de dizer do enunciador.

\footnotetext{
${ }^{3}$ Claro é que nem todas as situações de interação se pautam por um acordo efetivo entre os interlocutores. Sobre isso, ver Custódio Filho (2017).
} 
As investigações realizadas nos últimos anos a respeito do processo de recategorização demonstram que houve um redimensionamento nos critérios de definição desse objeto de estudo, que hoje é caracterizado, sobretudo, por ser alicerçado em aspectos de ordem textual, discursiva e cognitiva, o que comprova a sua natureza essencialmente pragmático-discursiva (LIMA; CAVALCANTE, 2015). A partir disso, as análises engendradas sob os pressupostos sociocognitivistas estão cada vez menos insistindo na obrigatoriedade da presença de uma expressão referencial para que haja a recategorização de um objeto de discurso.

Diante dessa constatação, defendemos, assim como Cavalcante (2011) e Custódio Filho (2011), que, atualmente, as pesquisas em torno da recategorização podem ser vinculadas a duas tendências, que não são antagônicas, mas complementares, visto que se entrecruzam pelos mesmos pressupostos de orientação sociocognitivista. Consoante Custódio Filho (2012), o que muda é o foco de análise, uma vez que os estudos da primeira tendência ${ }^{4}$ centram-se na manifestação e função das expressões referenciais recategorizadoras na cadeia textual, já os da segunda tendência ${ }^{5}$ privilegiam a integração dos elementos linguísticos e não linguísticos na construção da referência, que pode se manifestar independentemente de um sintagma nominal que homologue a transformação.

Vejamos, a seguir, dois exemplos de análise sobre o processo de recategorização. A análise do primeiro se vincula à primeira tendência; e a do segundo, à segunda tendência.

\begin{abstract}
$(1)^{6}$
Aconteceu em Minas: uma mulher traída cortou o cabelo da amiga... Pois é, foi assim mesmo. Uma descobriu que a outra tava saindo com o marido da uma. Complicado? Na verdade não... se fosse só a clássica história de traição não teria nada demais. Mas a mulher traída era uma pessoa que queria (e sabia como) se vingar. Sabendo que o ponto fraco feminino são as melenas, não contou tempo: cortou tudo! Isso mesmo, fez com que a amiga fosse pra casa careca. As mulheres sabem como se vingar... Mas a história não acaba aqui. A careca entrou na justiça e processou a "cabeleireira louca" em 4 mil e 800 reais. Sim, e mais 600 reais pela peruca... Pois é... coisas do universo feminino ${ }^{7}$.
\end{abstract}

Um mesmo objeto de discurso, estabelecido pelas expressões sublinhadas, apresentase de diversas formas, o que representa um processo de recategorização lexical. Com o

\footnotetext{
${ }^{4}$ Encontram-se pesquisas dessa natureza na obra de Koch e Elias (2009) e na de Cavalcante (2003).

${ }^{5}$ Exemplos de trabalhos vinculados à segunda tendência são os de Cavalcante (2011), Custódio Filho (2011), Cavalcante, Custodio Filho e Brito (2014), Brito (2010), Lima (2016) e Ferreira Neto (2018).

${ }^{6}$ Exemplo retirado de Custódio Filho (2011).

${ }^{7}$ Disponível em http://www.psicologoneurotico.blogger.com.br/2004_07_01_archive.html. Acesso em: 19 ago. 2008.
} 
desenvolvimento da leitura, são acrescidas especificidades ao objeto de discurso: além de ser uma mulher traída, ficamos sabendo que ela era "uma pessoa que queria (e sabia como) se vingar", por isso foi caracterizada como uma "cabeleireira louca". Essa última expressão é essencial para compreendermos o projeto de dizer do enunciador, pois demonstra o seu posicionamento sobre esse referente. Ante essas considerações, averiguamos que um mesmo objeto de discurso recebe diferentes formas referenciais, que modificam (recategorizam) seu status ao longo do texto. Com isso, percebe-se que o processo de recategorização propicia que os objetos de discurso sofram variações de natureza discursiva, por isso se modificam no seu desenvolvimento dentro da tessitura textual. Toda essa evolução é essencial para a progressão das ideias do texto, construindo o projeto de dizer do enunciador.

Percebe-se, nesse contexto, que uma investigação nesses moldes realiza uma análise direcionada à compreensão do caráter funcional das expressões referenciais na construção dos sentidos via textos. Ou seja, uma análise vinculada à primeira tendência de pesquisa sobre referenciação se restringe à manifestação e função das expressões referenciais para dar conta do processo de recategorização referencial.

Vejamos, agora, o segundo exemplo, cuja análise se vincula à segunda tendência de investigação.

\section{(2) ${ }^{8}$}

Que vergonha ver a atual prefeita censurar o uso de imagens de Ciro e Lula, grandes companheiros de Patrícia, no horário eleitoral! Será que essa prefeita tem vergonha de ver que Patrícia foi vice-líder de Lula no Senado??? Será que ela não se contenta em ver Lula longe dela, tal qual em 2004, quando o presidente estava com Inácio Arruda??? Antes era uma defensora da democracia, agora, no poder, se vestiu com as piores armas do autoritarismo e da censura! Liberdade de expressão JÁ! Patrícia é MULHER de RESPEITO e quer apenas ter o direito de mostrar a sua biografia, pena que a prefeita se [de]sespera com o passado histórico dela! ${ }^{9}$

O texto se refere a uma situação que ocorreu durante a campanha eleitoral para a prefeitura de Fortaleza (CE), em 2008: a coligação que apoiava a prefeita Luiziane Lins (PT), candidata à reeleição, vetou judicialmente as propagandas da concorrente Patrícia Saboia (PDT) em que esta aparecia ao lado do presidente Lula e do então deputado Ciro Gomes.

\footnotetext{
${ }^{8}$ Exemplo retirado de Custódio Filho (2011).

9 Texto recebido por e-mail.
} 
No Texto, ocorrem as recategorizações negativas do objeto de discurso "Luiziane Lins", que é apresentada como autoritária e competidora desleal. Entretanto, essa imagem não é construída diretamente por expressões referenciais. Essa representação é construída a partir de inferências engatilhadas pelas predicações. A recategorização de Luiziane Lins como autoritária provém da construção "se vestiu com as piores armas do autoritarismo e da censura". Já a recategorização da ex-prefeita como candidata desleal decorre das construções que informam que ela censura o uso de imagem dos, como se afirma no texto, grandes companheiros de Patrícia; tem vergonha de ver que Patrícia foi vice-líder de Lula no senado; não se contenta de ver Lula longe dela; e se desespera com o passado histórico de Patrícia. Com isso, concordamos com Custódio Filho (2011) que a estratégia de recategorização sem menção da expressão referencial é fundamental na construção dos sentidos dos textos, o que comprova que não é obrigatória a presença de um sintagma nominal para que um referente passe por uma transformação discursiva.

Em consonância com esses postulados, defendemos, pois, que o processo de recategorização não pode ser vinculado somente à utilização da expressão referencial, embora reconheçamos seu papel fundamental na construção da referência em qualquer texto. Não obstante, para a concepção de referenciação que adotamos, existem outras possibilidades altamente produtivas para realizar a recategorização referencial, promovendo, dessa maneira, a continuidade e a progressão textual (considerando-se estritamente o cotexto, podemos mencionar a participação de sintagmas adjetivais e de conteúdos proposicionais no acréscimo de traços aos referentes). Assim, reconhecemos, como Cavalcante e Matos (2016), que a recategorização consiste em um processo contínuo e complexo de transformações cognitivodiscursivas pelas quais os referentes passam no transcorrer de um texto.

Seguindo esta proposta de análise, buscamos confirmar a natureza multifacetada do texto. Vários fatores concorrem para a construção de sentidos, que não pode ficar restrita às expressões nominais. É primordial, portanto, uma investigação que priorize a língua em situações autênticas de interação e englobe os vários elementos contextuais que cercam o ato enunciativo, uma vez que a construção dos sentidos é resultado da integração de fatores linguísticos e extralinguísticos.

Dessa forma, a proposta didática de atividade de produção textual que implementamos baseia-se nos pressupostos preconizados pela segunda tendência dos estudos sobre referenciação, especificamente a partir dos trabalhos de Custódio Filho (2011, 2014), que determina a construção da referenciação por meio dos traços de sentidos e estabelece que a 
transformação dos referentes, devido a sua complexidade, não pode se limitar (embora isso seja importante) ao papel textual-discursivo assumido pelos sintagmas nominais responsáveis pela progressão referencial.

Em nossa sequência de ações didáticas, trabalhamos com contos que apresentam quebra de expectativa - textos em que, em algum momento da história, ocorre uma reviravolta no enredo. Em textos com essa característica, Custódio Filho (2011, 2014) preconiza que esses traços de sentidos se manifestam para pôr em evidência quatro "movimentos": apresentação, mudança por acréscimo, mudança por confirmação, mudança por correção.

Vejamos a seguir a definição para cada um desses movimentos.

O processo de apresentação refere-se ao modo pelo qual um referente se manifesta na primeira vez em que aparece. Claramente, esse processo ocorre somente uma vez. Entretanto, ele é uma etapa primordial para que os outros processos possam efetivar suas funções.

Após a apresentação, ocorre o processo de mudança, que engloba todos os acréscimos impingidos aos referentes, os quais permitem a verificação de que tais referentes modificam o estatuto de seus sentidos ao longo do texto. As mudanças podem ser divididas em três tipos: por acréscimo, por confirmação e por correção.

O movimento funcional de acréscimo abrange os casos que realizam modificações a um determinado referente, a partir da construção de traços de sentidos que mudam a situação inicial do objeto de discurso. Ressaltamos que os acréscimos não realizam uma ruptura em relação à compreensão que até então tenha sido feita, como acontece com a correção, que veremos adiante.

A etapa funcional de confirmação consiste na reiteração de algum traço já construído sobre o referente. Trata-se, portanto, de uma etapa em que se mantém o que já foi erigido por (re)elaborações anteriores. A fim de compreendermos bem essa etapa, devemos perceber que a confirmação, dificilmente, é apenas uma simples repetição de características; pelo contrário, ela representa uma estratégia de destaques necessários, visto que, quando uma confirmação ocorre, geralmente, há algum grau de mudança. Por exemplo, quando ocorre tal estratégia, pode-se destacar algum traço que antes não tinha sido ressaltado ou pode-se verificar uma mesma característica que já havia sido enfatizada a partir da ação do personagem em outro contexto. Custódio Filho (2011, p. 196) assevera que, em sequências narrativas mais longas, as estratégias de confirmação são ainda mais fundamentais: 
Parece-nos que a confirmação é um recurso essencial aos textos longos. No caso dos textos narrativos, a construção dos personagens e a verossimilhança que deve balizar suas ações carecem de uma ênfase em determinados traços. A cada vez que uma confirmação acontece, há um reconhecimento com alguma mudança, porque, por exemplo, a ênfase destacou algo que antes não vinha sendo ressaltado ou, ainda, uma mesma característica foi percebida a partir da ação do personagem em outro contexto. Se pensarmos que, mesmo nas narrativas em que não há quebra de expectativa, a evolução dos personagens pode passar por transformações radicais, podemos considerar que a confirmação tem a função de deixar ainda mais clara uma determinada representação para que, quando ocorrerem acréscimos e correções, os efeitos sejam ainda mais notados.

Pelo exposto acima, podemos perceber que a confirmação é uma estratégia referencial essencial na construção textual. Avaliamos que ela seja um mecanismo tão importante quanto o acréscimo e indispensável para que este seja plenamente efetivado na elaboração de sentidos.

A mudança por correção decorre das transformações direcionadas especificamente ao efeito de surpresa e/ou, possivelmente, nas mudanças no estatuto dos personagens as quais se encaminham em sentido oposto ao que se vinha estabelecendo até então. Evidentemente, as correções também são mudanças por acréscimo, porém, nesse caso, a modificação tem a função particular de corrigir a construção referencial, com o objetivo, sobretudo, de que a nova formulação cause impacto no interlocutor. Além disso, é óbvio que essa estratégia tem um contexto de ocorrência muito particular, o da instauração de uma quebra de expectativa, o que não necessariamente ocorre em todos os textos narrativos. Isso implica que, se, de um lado, os acréscimos e as confirmações são constitutivos de narrativas mais longas, de outro, as correções podem não ocorrer.

Defendemos, assim como Cavalcante e Brito (2016), que as mudanças por acréscimo, por confirmação e por correção correspondam ao processo da recategorização referencial e que elas ultrapassam os limites da expressão referencial, constituindo-se, portanto, na própria dinâmica da produção e interpretação textual.

A partir do panorama delineado, propomos, em nossa proposta de intervenção, um percurso metodológico-pedagógico que concebe o fenômeno da recategorização como um processo constituído por meio dos traços de sentidos, por compreendermos que este é um modelo mais complexo para dar conta do fenômeno, uma vez que contempla a integração de vários elementos que participam da configuração textual (superfície linguística, aparato cognitivo, aspectos sócio-históricos e circunstanciais) para a (re)construção de referentes. 
Assim, além dos sintagmas nominais, reconhecemos, como fatores determinantes da elaboração referencial, no que diz respeito aos elementos do cotexto, outros estratos da materialidade linguística, como o sintagma adjetival e as construções linguísticas formadas por predicações. Atestamos, assim, que a construção da referência se efetiva a partir da integração de diferentes partes da materialidade verbal, o que confirma a insuficiência da expressão referencial para o processo de construção de sentidos no decurso do ato de produção do texto.

Vejamos, então, a análise da referenciação por meio dos quatro "movimentos" funcionais na produção textual dos alunos com os quais aplicamos nossa proposta de intervenção pedagógica.

\section{Análise e discussão dos dados}

Neste trabalho, analisamos a construção da referência na produção final de um conto produzido pelos aprendizes ${ }^{10}$. Os alunos da nossa pesquisa estudavam em uma turma de $9^{\circ}$ ano do Ensino Fundamental de uma escola pública municipal de Fortaleza-CE, no ano de 2017.

A fim de preparar os discentes para a etapa de produção textual, realizamos um momento de "familiarização" com os elementos e as características da sequência narrativa e dos textos do gênero conto. Além disso, aplicamos duas atividades de compreensão textual com o gênero conto para colaborar com o aprendizado do papel dos processos referenciais.

Com isso, a expectativa de nosso estudo era desenvolver e aplicar uma sequência de atividades pedagógicas que visasse a contribuir na qualidade pragmático-discursiva da produção de textos pertencentes ao gênero conto escritos por alunos do $9^{\circ}$ ano do Ensino Fundamental de uma escola pública municipal de Fortaleza-CE, com enfoque no domínio das estratégias de construção das estratégias de referenciação. A partir disso, nossa hipótese básica era que o desenvolvimento e a aplicação de atividades pedagógicas com ênfase no domínio das estratégias de construção dos processos referenciais fossem um procedimento pedagógico pertinente para proporcionar um aprimoramento pragmático-discursivo da produção de textos escritos por alunos do ensino fundamental.

\footnotetext{
${ }^{10}$ Em nossa dissertação de mestrado, nossa análise consistiu de três etapas: 1) análise acerca das atividades de compreensão textual elaboradas e aplicadas na turma, para auxiliar os discentes na construção dos referentes; 2) análise da produção inicial e da intervenção docente para a produção final dos textos produzidos; 3) análise da construção da referência da produção final dos textos elaborados pelos aprendizes
} 
No que concerne à etapa de produção textual, os alunos, primeiramente, produziram a versão inicial dos textos, os quais nós analisamos, e, em seguida, realizamos o momento de interação professor-aluno para a reescrita dos contos produzidos. É importante salientar que o nosso papel foi como professor mediador no processo de produção textual. Assim, auxiliamos nas atividades de revisão e reescrita, favorecendo um melhor desenvolvimento pragmáticodiscursivo da produção textual por parte dos alunos. Podemos constatar, dessa forma, a importância da atividade de revisão do texto com o auxílio do professor como um meio que possibilita ao aluno refletir sobre o que escreveu e o que pode ser aprimorado, como uma atividade contínua de reflexão da escrita. $\mathrm{O}$ aluno deve sempre ser visto como o primeiro leitor de seu próprio texto, e o professor, como um mediador que debate, esclarece, pensa no processo de reformulação da produção textual. Planejamos que os discentes obtivessem a consciência de texto como um processo e das estratégias referenciais como mecanismos imprescindíveis na construção textual.

Após o término das atividades de revisão e reescrita, as versões finais dos contos produzidos foram digitadas para serem apresentados na escola. Dessa forma, os alunos que produziram os contos apresentaram os seus textos nas demais salas de aula da escola, para que os discentes e os professores tivessem acesso às produções, a fim de que os textos circulassem, possuindo, assim, uma importância social e objetivando que os produtores tivessem vontade de participar, não pensando que seria somente mais um texto para ser corrigido pelo professor para obter uma nota, mas uma atividade de autêntica interação social.

A seguir, transcrevemos a proposta de produção textual solicitada. O nosso objetivo, com essa proposta de produção textual, foi fazer com que os alunos produzissem uma narrativa na qual um dos personagens principais fosse construído por meio dos quatro movimentos funcionais: apresentação; mudança por acréscimo; mudança por confirmação; mudança por correção. 


\section{PROPOSTA DE PRODUÇÃO TEXTUAL ${ }^{11}$}

\section{Produção da primeira parte}

Uma narrativa com personagens interessantes e cenas emocionantes sempre conquista muitos leitores. Você já pensou em usar sua criatividade para escrever uma história assim? Então vamos tentar!

Você deve escrever um conto de suspense, que é caracterizado por mistério e por ações surpreendentes, inesperadas pelo leitor. Seu texto será dividido em duas partes. A primeira será produzida agora; a segunda será produzida posteriormente.

No conto que você vai escrever, deve ocorrer uma quebra de expectativa, ou seja, um dos personagens principais deve passar por uma transformação radical. Essa transformação em textos de suspense pode se dar da seguinte maneira: um dos personagens principais, aparentemente, age de forma correta, praticando ações consideradas normais ou boas, entretanto ele planeja e pratica determinadas ações inesperadas, que mudam seu estatuto de personagem "bom" para personagem "mau", uma vez que essas ações prejudicam bastante outro personagem de maneira que o leitor não espere que isso ocorra.

No desenvolvimento da primeira parte de seu texto, é importante criar algumas pistas sutis que já demonstram que o personagem irá passar por uma grande transformação, entretanto deixe para efetivar essa transformação somente na segunda parte, através de ações explícitas praticadas pelo personagem, que prejudicarão outra personagem importante da narrativa.

Uma estratégia importante que você deve utilizar é a criação de diálogos entre os personagens, tanto nessa parte do texto quanto na próxima.

Quadro 1 - Primeira parte da proposta de produção textual. Fonte: elaboração dos autores, Fortaleza, 2018.

\footnotetext{
${ }^{11}$ A proposta de produção textual é baseada em um material pedagógico produzido por Custódio Filho.
} 
Planeje a primeira parte de seu texto a partir das perguntas do quadro a seguir.

\section{Personagens}

Quem são os personagens de sua história?

Quem são os personagens principais?

$>$ Quais são as características dos personagens?

Qual personagem passará pela grande transformação?

\section{Lugar}

Onde a história acontece?

Como é esse lugar?

\section{Tempo}

A história acontece no passado, nos dias atuais ou no futuro?

Se for no passado, é um passado mais recente ou mais antigo?

Se for no futuro, que características o cenário deve apresentar?

\section{Ação}

Qual é o problema que o personagem principal deve enfrentar?

Como o personagem se envolve no problema?

Que complicações vão aparecer por causa desse problema?

Qual a causa de o personagem passar por uma grande transformação? 
Lembre-se de que a primeira parte de seu texto deve terminar com uma cena inacabada que desperte a curiosidade no leitor. Como essa será apenas a primeira parte da história, antes de concluir, planeje como será a continuação.

No final da tarefa, todos da turma lerão suas histórias e poderão escolher quais textos têm a cena final mais emocionante.

Antes de começar a escrever, discuta com seu professor e seus colegas o planejamento do texto.

- Para que você vai produzir o texto?

- Quem vai ler o texto?

- Que nome recebe esse texto?

- Quais são as partes desse texto?

- Onde ele vai aparecer?

Quadro 2 - Planejamento da primeira parte da proposta de produção textual. Fonte: elaboração dos autores, Fortaleza, 2018.

\section{PROPOSTA DE PRODUÇÃO TEXTUAL}

\section{Produção da segunda parte}

Na parte anterior do seu texto, você iniciou um conto de suspense escrevendo a primeira parte da história. Agora é a hora de a narrativa continuar.

Lembre-se de que, no desenvolvimento de sua história, um dos personagens principais deve passar por uma transformação radical, de acordo com o que havia sido planejado antes da produção da primeira parte do texto.

Lembre-se, também, de que você deve criar diálogos entre os personagens.

Não repita aquilo sobre o que já falou na primeira parte da história, a não ser que essa repetição seja necessária para que os leitores lembrem algo importante sobre o enredo.

Agora, mãos à obra! Releia o texto que você produziu e proponha uma continuação que parta do ponto onde parou. Você pode escolher vários caminhos. Vamos sugerir dois:

você pode propor um fechamento para a situação em que a parte 1 terminou e, em seguida, construir uma ou mais situações emocionantes, que culminem na quebra de expectativa no final do texto;

você pode complicar ainda mais a situação final da parte 1, para depois construir a quebra de expectativa no final do texto.

O que importa é que você siga as informações que você mesmo criou na primeira parte do texto e não crie nada que prejudique o sentido do texto, buscando um final o mais surpreendente possível. 
Quadro 3 - Segunda parte da proposta de produção textual. Fonte: elaboração dos autores, Fortaleza, 2018.

Neste artigo, analisamos o texto "A influência de um deus", feito por um grupo de três alunos $^{12}$. O enredo mostra o protagonista - Jack, um jornalista ambicioso, - tentando realizar uma reportagem sobre um local no qual estão sendo realizados sacrifícios humanos. Ele convence sua esposa, Annye, a acompanhá-lo nessa empreitada, embora ela não quisesse ir. Nesta análise, focalizamos a construção da referência do personagem Jack..

Destacamos, nos dados apresentados, os estratos da materialidade linguística que competem para a construção do referente selecionado. A visualização desses estratos se dá mediante a utilização da seguinte legenda:

\section{Expressão referencial que incide sobre o referente escolhido: negritada}

Sintagma adjetival em função de predicativo ou oração subordinada adjetiva explicativa que contribui para a (re)elaboração do referente escolhido: sublinhado

[Predicação (completa ou incompleta) que contribui para a (re)elaboração do referente escolhido: colocada entre colchetes (cada construção recebe um número, que a identifica dentro da análise)]

Expressão referencial que incide sobre objetos de discurso diferentes do referente escolhido: italicizada

Quadro 4 - Categorias de análise da construção do personagem Jack. Fonte: elaboração dos autores, Fortaleza, 2018.

Passemos, agora, à análise, efetivamente, do texto, a qual é feita por meio dos fragmentos textuais.

$1^{\circ}$ fragmento

A influência de um deus

Annye acordou com [(1) Jack escutando uma notícia que o deixou muito animado: "atualmente, a única informação que temos sobre o local é que são utilizados humanos para algum tipo de ritual de sacrifício..."]

\footnotetext{
${ }^{12}$ No total, foram analisados, em nossa proposta de intervenção, dez textos.
} 
- Jack, você parece estar feliz com essa notícia e eu realmente espero estar errada. Falou Annye, apreensiva.

- [(2) Amor, se nós conseguirmos informações sobre o caso, ficaremos famosos. $]$ Falou Jack, com uma expressão de ânimo.

- Se até hoje ninguém teve a brilhante ideia de ir a um local macabro como esse, nós não seremos os primeiros.

- Annye...

- Eu não irei.

No primeiro parágrafo do texto, reconhecemos a primeira etapa funcional da construção do referente: a apresentação. O personagem é apresentado por meio de uma expressão referencial que designa o seu nome próprio "Jack". Ainda no primeiro parágrafo, o referente sofre a primeira mudança por acréscimo, através do sintagma adjetival: "muito animado". Entretanto, para compreendermos bem essa característica erigida, é fundamental o conteúdo completo da construção 1: o que deixa Jack animado é uma notícia sobre pessoas sendo sacrificadas, o que nos faz pensar, inicialmente, que ele seja uma pessoa cruel, pois, aparentemente, anima-se com o sofrimento dos outros. Daí a importância de levarmos em conta, como enfatiza Custódio Filho (2011), o teor completo da informação para a construção dos objetos de discurso.

Através da construção 2, temos outro acréscimo do personagem: ele é uma pessoa ambiciosa, que deseja conquistar fama através de seu trabalho profissional, mesmo à custa do sofrimento de outras pessoas, por isso a sua animação com a notícia que ele ouviu, pois vê nela uma chance de conseguir seu objetivo de sucesso profissional.

Destacamos, também, nesse fragmento, a importância das seguintes expressões referenciais que incidem sobre objetos de discurso diferentes do referente escolhido: "Amor" e "uma expressão de ânimo". Por meio da primeira expressão, percebemos que existe algum tipo de relacionamento amoroso entre Jack e Annye e que ele a trata de forma carinhosa. Vemos, assim, que essa expressão recategoriza, diretamente, a personagem Annye, mas serve, também, mesmo que indiretamente, para caracterizar o personagem Jack. Quanto à segunda expressão, é por meio dela que ocorre a primeira confirmação de Jack: ele está, realmente, animado com a notícia recebida. Ou seja, o objeto de discurso "uma expressão de ânimo" tem como papel fundamental construir o sentido de outro objeto de discurso, Jack.

Observamos, já nesse primeiro fragmento, a eficácia das construções linguísticas para a configuração do referente. Os traços de sentidos construídos sobre o personagem advêm da "participação" das diferentes estruturas linguísticas no processo de produção de sentidos.

Continuemos nossa análise, com o próximo excerto do texto. 
(4)

\section{$2^{\circ}$ fragmento}

Jack ficou decepcionado por Annye não apoiar a sua ideia e foi pensar sobre o que ocorreu em seu quarto. [(1) "Como eu a convencerei de que é importante nós irmos até lá? Não posso perder essa oportunidade, pois não terei outra tão facilmente."]

Annye viu seu marido sozinho em seu quarto. Ela hesitou, mas depois falou:

$-\mathrm{O}$ que faz aqui sozinho, Jack?

- Hã? Que susto, Annye. [(2) Estou apenas pensando em meu trabalho.]

- Ah...sei. Eu já disse que não vou. [(3) Não precisa planejar nada, não perca seu tempo.]

- Tudo bem. Eu sabia que você teria medo.

- E tenho mesmo. Eu já lhe disse isso.

[(4) - Bons jornalistas não teriam.] [(5) Eu, que tenho muito orgulho do meu trabalho, faço tudo por ele.]

- Eu não me importo!

[(6) - Sempre fiz tudo por você!] Sou amoroso, atencioso, além dos vários presentes que lhe dou e ainda [(7) ajudo você no trabalho], mas, mesmo necessitando de sua ajuda, [(8) você nunca faz nada por mim!] [(9) É assim que você retribui: com indiferença! Tenho vontade de largar tudo!]

Annye saiu do quarto furiosa e [(10) Jack continuou a pensar como a convenceria de ir com ele ao local.]

Neste excerto, destacamos como confirmações os seguintes traços (acompanhados dos substratos linguísticos que os sustentam):

- Jack é uma pessoa que prioriza, excessivamente, seu trabalho (construções 2 e 5 e a oração adjetiva explicativa "que tenho muito orgulho do meu trabalho");

- ele está convencido em ir junto com sua esposa ao local onde estão ocorrendo os sacrifícios (construções 1 e 10);

- ele, realmente, tem uma relação amorosa com Annye (expressão referencial "seu marido" e construções 6 e 7).

Os acréscimos decorrentes da leitura desse fragmento são que Jack é uma pessoa que gosta de planejar o que pretende fazer (construções 1, 3 e 10), que subestima a qualidade profissional de sua esposa (construção 4), que é uma companheiro amoroso e dedicado (construções 6 e 7, sintagmas adjetivais "amoroso" e "atencioso" e a expressão referencial que incide sobre objetos de discurso diferentes do referente escolhido "os vários presentes que lhe dou") e que considera que sua esposa não é tão boa companheira quanto ele (construções 8 e 9 e a expressão referencial que incide sobre objetos de discurso diferentes do referente escolhido "vontade de largar tudo"). 
Apresentamos, a seguir, o próximo fragmento, seguido da análise sobre a referenciação envolvendo o personagem destacado.

\section{$3^{\circ}$ fragmento}

No dia seguinte, Annye acordou bem cedo por causa da conversa de Jack ao telefone. Ele parecia estar muito assustado e nervoso e [(1) gritava que não poderia ser verdade o que estavam falando.]

Após ele desligar o telefone, Annye lhe perguntou o que estava acontecendo.

- Foi meu amigo Max, cunhado de Johnny, que me ligou! Annye, meu primo Johnny foi capturado por aqueles assassinos que estavam passando na reportagem.

[(2) Não acredito que eles irão sacrificar meu primo]. [(3) Tenho que fazer alguma coisa.]

- Que assassinos?

- Os que você não queria ir até o local procurar informações.

- Não acredito.

- Acredite e [(4) eu irei lá!]

- Não, Jack! Você não vai!

[(5) - Eu preciso buscar meu primo, ele é importante pra mim!]

- Mas [(6) você vai correr o risco de ser capturado também!]

[(7) - Isso não é o que importa pra mim! Eu irei!]

Jack se dirigiu ao seu carro e Annye lhe disse:

- Calma! Eu também irei.

Esse excerto é essencial na construção da narrativa, pois, nele, apresenta-se o motivo que convence Annye a ir com Jack ao local onde estão ocorrendo os sacrifícios: o sequestro do primo de seu esposo. Destacam-se, sobretudo, na leitura desse fragmento, dois acréscimos fundamentais para a construção do personagem Jack:

- ele tem muito apreço pelo seu primo Jhonny (construções 1, 2, 3 e 5 e os sintagmas adjetivais "muito assustado" e "nervoso");

- ele é uma pessoa que não tem medo de correr riscos (construções 4, 5, 6 e 7).

Passemos, então, ao próximo fragmento.

(6)

$4^{\circ}$ fragmento

Os dois arrumaram o que precisavam e seguiram o caminho para ir até o local. Durante o percurso, era notável que as casas iam ficando cada vez mais raras.

- Jack, pra que estamos vindo aqui? Nós não precisamos fazer isso, olhe esse lugar!

- Meu primo...

- O que é aquilo? - Annye ficou espantada com o que viu.

- O que você viu, Annye?

-Tinha alguém ali.

Jack parou o carro no meio da estrada.

[(1) - Pegue sua câmera, vamos ver o que pode ser.]

- Eu não o vejo mais.

- Não tem nada, viu só?! Era loucura sua. 
- Olhe! - Annye havia achado um livro, algo semelhante a uma bíblia, ela resolveu abrir. - Aqui diz: "acredite em minha existência, os que hesitarem não terão a minha salvação". Vemos que tudo isso envolve religião. Já é um fragmento para a nossa busca. Jack? O que está fazendo aí? Jack!

- Olhe... ali tem uma casa.

- Você vai lá?

[(2) - Claro que vou, Annye! Pode ter algo importante lá, pois é a única casa que vimos até agora nesse local imenso.]

[(3) - Você sempre gosta de se arriscar, Jack?]

- Sim, Annye. - Jack sussurra. - Cuidado!

A casa estava vazia, mas havia um buraco no chão, possivelmente feito a mão e próximo a ele havia um bloco que se encaixava perfeitamente.

- Olhe, um flip book.

Jack resolveu olhar cada página do flip book.

- Aqui tem uma animação, Annye. Parece ser pessoas louvando algum tipo de deus.

- Então o jornal estava certo, os humanos que eram trazidos para cá eram utilizados para algum tipo de sacrifício.

O céu ficou tomado por nuvens e começou uma forte chuva.

- Ótimo, era só o que faltava. - Falou Annye, cada vez mais assustada.

[(4) - Podemos passar a noite aqui.] - Rebateu Jack, que aparentava estar calmo.

- Você está louco, Jack!?

[(5) - Eu trouxe alguns cadeados e uma cama inflável.]

[(6) - Parece até que tudo isso é planejado.]

- Eu sempre ando precavido, amor.

O fragmento traz confirmações importantes ao referente. Jack, realmente, não tem medo de se arriscar (construções 2, 3 e 4, a oração adjetiva explicativa "que aparentava estar calmo" e o sintagma adjetival "louco") e ele é uma pessoa que planeja bem o que faz (construções 5 e 6 e o sintagma adjetival "precavido").

Continuemos nossa análise, com o próximo trecho do conto.

\section{$5^{\circ}$ fragmento}

Os dois colocaram os cadeados nas portas, encheram a cama e foram dormir. [(1)

Jack teve um sonho.]

"Hã? Onde estou? Tem alguém aí?"

"Você deve fazer isso."

"Quem está aí?"

"Jack, não!"

"Annye!"

"Você não pode se arrepender."

"Quem é você? Quem está falando comigo?"

"Você me conhece, Jack. Apenas...."

- Jack? Acorda!

- Hã? - Ele acordou assustado.

[(2) - Por que você estava gritando meu nome?] Estava tendo algum pesadelo?

- Sim, Annye, mas não quero falar sobre isso.

- A chuva não passou, mas podemos continuar a nossa pesquisa. [(3) Jack, você está bem?]

- Estou. Não se preocupe, só estou meio abalado.

- Esqueça, já passou.

Os dois decidiram ir até o carro, mas ele já não estava mais lá.

- Eu já esperava por isso, Jack! [(4) Viu onde você foi nos meter?!] 
[(5) - Não podemos ficar aqui, vamos em busca de mais alguma coisa!]

Eles caminharam entre as árvores, para não serem vistos por algo ou alguém, até que avistaram um povoado.

- Jack, vamos parar para um lanche?

- Annye, olhe! Um povoado!

- Até que enfim!

- Espere, têm várias pessoas ali.

Eles foram se aproximando aos poucos. Chegaram a um local para ter uma visão nítida das pessoas que ali estavam.

[(6) - Nunca tinha visto algo assim antes!] Annye, você vê que eles estão ajoelhados e olhando para uma cadeira?

- É meio estranho, aliás, muito estranho.

Nesse fragmento, é essencial, para a construção do personagem Jack, o conteúdo englobado pela introdução encapsuladora ${ }^{13}$ "sonho". Pode-se perceber que o personagem fica atormentado com alguém que, aparentemente, está o obrigando a fazer alguma coisa. Nesse sentido, a partir da leitura desse excerto, temos as seguintes características acrescentadas de Jack:

- ele está nervoso e perturbado com algo (construções 2 e 3 e os sintagmas adjetivais "assustado e meio abalado");

- ele parece ficar surpreso com a cena que presencia com sua esposa (construção $6)$.

Como confirmações decorrentes da leitura desse fragmento, temos que Jack não tem medo de colocar a si e sua esposa em situações perigosas (construção 4) e que ele está determinado em fazer a pesquisa para seu trabalho (construção 5).

No conto analisado, a correção se manifesta na leitura do próximo fragmento.

$6^{\circ}$ fragmento

[(1) Jack foi ao encontro das pessoas, chegou próximo a uma casa e encontrou mais um documento.]

- Jack, volta aqui!

Ele acenou.

- Annye, cuidado!

- Com o quê?

- Hahaha..Com isso!

- Socorro, Jack!

[(2) - Agora podemos iniciar!]

13 O termo introdução encapsuladora é usado por Silva (2013) para remeter aos casos em que há um encapsulamento prospectivo (FRANCIS, 2003), ou seja, quando o termo encapsulador aparece antes do conteúdo encapsulado. 
[(3) - Você só pode estar brincando, Jack!]

[(4) Todos abriram caminho para a passagem de Jack até a cadeira.]

[(5) - Eu preciso fazer isso, amor! É um pedido do meu deus!] - O rapaz, que estava com um semblante muito feliz, falou enquanto era saudado por todos.

- Muito bem, nosso querido irmão! [(6) Nosso deus tem muito orgulho de você!! -

Todos falaram sorridentes.

[(7) - Eu faço tudo pelo nosso deus!] Tenho muito amor por ele.

- Tudo o que você me contou de seu primo era mentira?

- Não! [(8) Eu também o trouxe há alguns dias com a ajuda de Max!]

O essencial desse fragmento, evidentemente, é a quebra de expectativa gerada pela revelação (correção) de que Jack não estava preocupado em fazer uma pesquisa para seu trabalho nem em procurar seu primo, mas, sim, em levar sua esposa para ser sacrificada, uma vez que ele faz parte da seita. Além disso, é fundamental percebermos que ele também já havia levado seu primo para ser sacrificado, o que demonstra o quanto ele é frio e perverso. Vários estratos da materialidade linguística participam para que a transformação ocorra plenamente. Destacamos, dentre outros, os seguintes:

- as expressões referenciais que incidem sobre objetos de discurso diferentes do referente escolhido: "meu deus", "semblante muito feliz" e "muito amor por ele".

- as construções 2, 4, 5, 7 e 8;

• a expressão referencial "nosso querido irmão".

A partir da transformação pela qual o referente passa, um conjunto de traços anteriormente construídos são negados ou reformulados. Destacamos, a seguir, os principais:

- Jack não está preocupado em ficar famoso pelo seu trabalho de jornalista;

- ele não é um companheiro dedicado e amoroso, mas, sim, um marido perverso e traiçoeiro;

- ele não tem qualquer apreço pelo seu primo Jhonny.

Verificamos, na análise empreendida, que a produção textual dos alunos contemplou os quatro movimentos funcionais para a construção do personagem Jack. Ademais, demonstramos que os discentes utilizaram um aparato linguístico diversificado para a configuração dos traços de sentidos: expressões referenciais (sintagmas nominais) - tanto aquelas que dizem respeito a um referente central quanto aquelas que se referem a outros 
referentes que sejam importantes para a configuração do referente central; sintagmas adjetivais e predicações.

Nesse contexto, enfatizamos que a investigação sobre a construção referencial não pode se restringir, apesar do seu papel indispensável, ao uso das expressões referenciais, principalmente em textos mais longos, haja vista o teor completo da informação, a partir do método de análise por meio dos traços de sentidos proposto por Custódio Filho (2011, 2014), parecer ser um procedimento mais eficaz na configuração da referência e, consequentemente, na produção textual.

Em nossa análise, intentamos ressaltar o caráter sociocognitivo da referência, visto que optamos por destacar a funcionalidade da relação entre os elementos do texto. $\mathrm{O}$ cerne foi, então, a função textual-discursiva que as construções referenciais exercem no texto, a fim de construírem, em conjunto, a produção de sentidos. Destaca-se, assim, que os diversos recursos disponíveis no texto são, a nosso ver, os responsáveis para a construção de determinada função referencial.

Nesse sentido, pensamos que conseguimos fazer os alunos compreenderem que, na construção dos objetos de discurso, eles podem utilizar várias formas referenciais. Entretanto, esclarecemos que essas formas devem ser as mais adequadas à situação de interação. Assim, nosso pensamento está em consonância com os pressupostos de Cavalcante, Custódio Filho e Brito (2014, p. 39), que afirmam que o aprendiz, na prática de produção e leitura, "deve ser estimulado a utilizar estratégias que explicitem a aplicação desse princípio. Ele deve entender que o uso da linguagem passa pela aceitação da audiência, o que demanda uma antecipação sobre como representar os referentes". Além disso, os autores defendem que os professores devem incentivar os alunos a "negociarem" com os textos que leem/escutam, para que, a partir daí, eles possam participar, também, da construção dos conhecimentos provenientes dos textos. Ou seja, o contato com outros textos também é fundamental para preparar o aprendiz na produção de seu próprio texto.

Assim, consideramos que o tratamento dos fenômenos referenciais, sob a perspectiva sociocognitivo-discursiva, pôde aprimorar o desempenho pragmático-discursivo do produtoraprendiz em processos de produção textual. Os estudos da referenciação mostraram-se uma opção eficaz para a exploração da construção de sentidos na tessitura textual, o que favoreceu o ensino-aprendizagem da produção escrita em sala de aula.

Defendemos, desse modo, que a construção referencial resulta da integração de diferentes recursos, por isso almejamos, em nossa análise, apresentar os variados estratos que 
promovem as modificações dos referentes no decurso da produção e interpretação textual. Esforçamo-nos nesse objetivo, pois assumimos que a referenciação é um processo dinâmico e complexo e somente a natureza sociocognitivo-discursiva do texto pode dar conta da construção dos sentidos (MONDADA; DUBOIS, 2003; CAVALCANTE, 2011; CUSTÓDIO FILHO 2011; CAVALCANTE; CUSTÓDIO FILHO; BRITO, 2014).

\section{Considerações finais}

Neste artigo, intencionamos demonstrar que o estudo sistemático da referenciação, sob a perspectiva sociocognitivo-discursiva, e o papel do professor como um mediador são recursos fulcrais para o desenvolvimento pragmático-discursivo da produção textual por parte dos alunos, o que comprova que os pressupostos preconizados pela proposta teórica da referenciação podem fornecer procedimentos metodológico-pedagógicos exequíveis para o ensino-aprendizagem de Língua Portuguesa na educação básica.

Além disso, pretendemos demonstrar que as análises sobre a construção das estratégias de referenciação não podem ser restritas ao uso das expressões referenciais, embora elas possuam um papel fundamental na construção da referência. Assim, enfatizamos que a investigação sobre o teor completo da informação, por meio dos traços de sentidos, apresentase como um procedimento profícuo na configuração da referência.

Com isso, acreditamos ter contribuído em demonstrar que é possível realizar um trabalho docente que se baseie nos pressupostos teóricos da referenciação, o qual possa, entre outros objetivos, conscientizar os aprendizes sobre as formas mais eficazes para eles construírem e reconstruírem os objetos de discurso em suas produções textuais.

\section{Referências}

BRITO, M. A. P. Marcas linguísticas da interpretação psicanalítica: heterogeneidades enunciativas e construção da referência. 2010. 213 f. Tese (Doutorado em Linguística) Programa de Pós-Graduação em Linguística, Universidade Federal do Ceará, Fortaleza, 2010.

CAVALCANTE, M. M. Os sentidos do texto. São Paulo: Contexto, 2012.

Referenciação: sobre coisas ditas e não ditas. Fortaleza: UFC, 2011.

Expressões referenciais - uma proposta classificatória. Caderno de Estudos Linguísticos. Campinas, SP, v. 10, n. 44, p. 105-118, jan./jun. 2003. 
CAVALCANTE, M. M.; MATOS, J. G. Discutindo as marcas avaliativo-argumentativas das recategorizações. Intersecções. Jundiaí, SP, v. 18, n. 1, p. 93-111, fev. 2016.

CAVALCANTE, M. M.; BRITO, M. A. P. O caráter naturalmente recategorizador das anáforas. In: AQUINO, Z. G. O.; GONÇALVES-SEGUNDO, P. R. (Org.). Estudos do discurso: caminhos e tendências. São Paulo: Paulistana, 2016, p. 119-133.

CAVAlCANTE, M. M.; CUSTÓDiO FILHO, V.; BRITO, M. A. P. Coerência, referenciação e ensino. São Paulo: Cortez, 2014.

CUSTÓDIO FILHO, V. Rediscutindo o princípio de construção negociada dos objetos de discurso. Revista de Letras. Fortaleza, CE, v. 2, n. 36, p. 63-77, jul./dez. 2017.

. Análise da referenciação por meio de traços de significação. In: FIGUEIREDO, M. F. et al (Org.). Textos: sentidos, leituras e circulação. Franca, SP: Unifran, 2014, p. 199-224.

Reflexões sobre a recategorização referencial sem menção anafórica. Linguagem em (Dis)curso. Tubarão, SC, v. 12, n. 3, p. 839-858, set./dez. 2012.

Múltiplos fatores, distintas interações: esmiuçando o caráter heterogêneo da referenciação. 2011. 329 f. Tese (Doutorado em Linguística) - Programa de Pós-Graduação em Linguística, Universidade Federal do Ceará, Fortaleza, 2011.

FERREIRA NETO, J. A. Desenvolvimento de estratégias de referenciação na produção de textos narrativos: uma proposta de interação professor-aluno. 2018. 218 f. Dissertação (Mestrado Profissional em Letras), Universidade Estadual do Ceará, Fortaleza, 2018.

FRANCIS, G. Rotulação do discurso: um aspecto da coesão lexical de grupos nominais. Tradução Mônica Magalhães Cavalcante, Valéria Sampaio Cassan de Deus e Thatiane Paiva de Miranda. In: CAVALCANTE, M. M.; BIASI-RODRIGUES, B.; CIULLA e SILVA, A. (Org.). Referenciação. São Paulo: Contexto, 2003, p. 191-228.

KOCH, I. G. V.; ELIAS, V. M. Ler e escrever: estratégias de produção textual. São Paulo: Contexto, 2009.

KOCH, I. G. V.; CUNHA-LIMA, M. L. Do Cognitivismo ao Sociocognitivismo. In: MUSSALIM, F.; BENTES, A. C. (Org.). Introdução à Linguística. v. 3: fundamentos epistemológicos. 2. ed. São Paulo: Cortez, 2005, p. 251-300.

LIMA, S. M. C. A construção de referentes em textos verbo-visuais: uma abordagem sociocognitiva. Intersecções, Jundiaí, SP, v. 18, n. 1, p. 61-80, fev. 2016.

LIMA, S. M. C.; CAVALCANTE, M. M. Revisitando os parâmetros do processo de recategorização. Revista Virtual de Estudos da Linguagem, v.13, n. 25, p. 295-315, jun./jul. 2015. Disponível em http://www.revel.inf.br/files/357d083dd43195695b2541a9bde1b43d.pdf. Acesso em 29 mai. 2018. 
MONDADA, L.; DUBOIS, D. Construção dos objetos de discurso e categorização: uma abordagem dos processos de referenciação. Tradução Mônica Magalhães Cavalcante. In: CAVALCANTE, M. M.; BIASI-RODRIGUES, B.; CIULlA e SILVA, A. (Org.). Referenciação. São Paulo: Contexto, 2003, p. 17-52.

SILVA, F. O. Formas e funções das introduções referenciais. 2013. 126 f. Tese (Doutorado em Linguística) - Programa de Pós-Graduação em Linguística, Universidade Federal do Ceará, Fortaleza, 2013.

Recebido em 31 de maio de 2018. Aprovado em 10 de outubro de 2018. 